\title{
Structural components of the nuclear body in nuclei of Allium cepa cells
}

\author{
TAO WeI ${ }^{1}$, Chang Hui YAN ${ }^{1}$, Tao $\mathrm{CAI}^{1}$, Shui $\mathrm{HAO}^{2}$, Zhong He ZHAI ${ }^{1, *}$ \\ 1 College of Life Sciences, Peking University, Beijing 100871, China \\ 2 Institute of Genetics and Cytology, Northeast Normal University, Changchun Jilin 130024, China
}

\begin{abstract}
Nuclear bodies have long been noted in interphase nuclei of plant cells, but their structural component, origin and function are still unclear by now. The present work showed in onion cells the nuclear bodies appeared as a spherical structure about 0.3 to $0.8 \mathrm{~mm}$ in diameter. They possibly were formed in nucleolus and subsequently released, and entered into nucleoplasm. Observation through cytochemical staining method at the ultrastructural level confirmed that nuclear bodies consisted of ribonucleoproteins (RNPs) and silverstainable proteins. Immunocytochemical results revealed that nuclear bodies contained no DNA and ribosomal gene transcription factor (UBF). Based on these data, we suggested that nuclear bodies are not related to the ribosome or other gene transcription activities, instead they may act as subnuclear structures for RNPs transport from nucleolus to cytoplasm, and may also be involved in splicing of pre-mRNAs.
\end{abstract}

Key words: Nuclear body, structural component, ribonucleoproteins, nucleolus, Allium cepa.

\section{INTRODUCTION}

Small spherical nuclear bodies have long been observed in both animal and plant interphase nuclei. In the case of animal cells, these nuclear bodies are generally called coiled bodies[1]. As for plant cells, they have been variously described as coiled bodies, karyosomes, micronucleoli or nucleolus-associated bodies because they sometimes appeared in the vicinity of nucleolus[2-4]. Early cytologists noted that nuclear bodies in plant cells appeared as a tangle of coiled threads forming a round mass, and their size varied from 0.8-1.5 $\mu \mathrm{m}$ [5]. During recent years, as a result of the utilization of immuno- electron microscopy, it has been shown that nuclear bodies in plant cells contain snRNP (small nuclear ribonucleoproteins), which is involved in the splicing machinery of a wide variety of cell types[6]. Some workers also have obtained experimental evidence in favor of an intimate association of these bodies with nucleolus[7].

*Corresponding author: Prof.ZhongHe ZHAI.

E-mail: zzhcbpku@public.bta.net.cn

Received Nov-8-2000. Revised Dec-26-2000. Accepted Jan-92001.
Although nuclear bodies have been characterized during the last few years, the structural components of nuclear bodies are still not determined, and their origin and role also remain obscure.

Our main aims in the present work were to investigate the presence of RNPs and proteins in nuclear bodies, especially to verify whether these bodies in plant cells contain DNA molecules by using onion cells as the experimental materials. Finally, since the nuclear bodies are usually closely associated with nucleolus, we further verified whether the nuclear bodies are detached from nucleolus and whether they are related to the transcription activity of rRNA genes in nucleolus.

\section{MATERIAL AND METHODS}

\section{Tissue}

Root tip meristem of Allium cepa was used as the material in this study. Root tip meristem was obtained from onion bulbs grow at $15^{\circ} \mathrm{C}$.

\section{Conventional electron microscopy}

Root tips were carefully excised and fixed in $2.5 \%$ glutaraldehyde in $0.1 \mathrm{M}$ phosphate buffer saline (PBS) $\mathrm{pH} 7.4$ for $2 \mathrm{~h}$ at 
room temperature. After rinsing in distilled water for $20 \mathrm{~min}$, they were postfixed in $1 \%$ osmium tetroxide for $60 \mathrm{~min}$. Samples were dehydrated in an ethanol-acetone series and embedded in Epon 812. Ultra-thin Sections of $60-80 \mathrm{~nm}$ thick were stained with uranyl acetate and lead citrate, and observed under a Hitachi600B transmission electron microscope.

\section{Ultrastructural cytochemistry for RNPs}

The EDTA regressive staining for ribonucleoproteins was performed according to Bernhard[8]. Briefly, ultra-sections were treated as follows: $5 \%$ uranyl acetate, $20 \mathrm{~min}$; $0.2 \mathrm{M} \mathrm{EDTA,} 5 \mathrm{sec}$; and lead citrate, $30 \mathrm{sec}$. Then sections were observed under a Hitachi-600 transmission electron microscope.

\section{Electron microscopic silver-staining}

Root tips were excised and immediately fixed with $4 \%$ paraformaldehyde and $2.5 \%$ glutaraldehyde in $0.1 \mathrm{M}$ phosphate buffer saline (PBS) $\mathrm{pH} 7.4$ for $2 \mathrm{~h}$ at $4^{\circ} \mathrm{C}$. After treated with $\mathrm{AgNO}_{3}(50 \%)$ solution for $24-48 \mathrm{~h}$ at $50^{\circ} \mathrm{C}$, the root tips were washed in $5 \%$ sodium thiosulfate, then dehydrated and embedded in Epon812.

\section{Processing for Lowicryl K4M embedding}

Lowicryl K4M was bought from Chemische Werke Lowi GMBH and Co in Germany.

Samples were fixed in 3\% glutaraldehyde and $4 \%$ formaldehyde in PBS for $2 \mathrm{~h}$. After washing in distilled water three times, $30 \mathrm{~min}$ each, they were dehydrated in an ethanol series and permeated with $100 \%$ ethanol: $\mathrm{K} 4 \mathrm{M}$ (1:1) mixture for $12 \mathrm{~h}$ at $0^{\circ} \mathrm{C}$, $100 \%$ ethanol:K4M(1:2)mixture for $1 \mathrm{~h}$ at $-10^{\circ} \mathrm{C}$, and $100 \% \mathrm{~K} 4 \mathrm{M}$ for $60 \mathrm{~h}$ at $-30^{\circ} \mathrm{C}$. After that they were embedded in Lowicryl K4M at $-30^{\circ} \mathrm{C}$ under UV irradiation for over $24 \mathrm{~h}$, then irradiated again for 2-3 d under room temperature.

\section{Immuno-localization of anti-DNA antibody}

The anti-DNA monoclonal antibody was purchased through Boehringer Mannheim. The second antibody (goat anti-mouse IgM) coupled with colloidal gold particles $(10 \mathrm{~nm})$ was purchased from Sigma.

For immunolabelling, Lowicryl K4M Embedded ultrathin sections mounted on nickel grids were floated on PBS plus $0.5 \%$ Triton X-100 for $10 \mathrm{~min}$ at room temperature and then incubated with normal goat serum for $20 \mathrm{~min}$ at $37^{\circ} \mathrm{C}$. Then sections were incubated with anti-DNA antibody, diluted 1: 2 in PBS, for $30 \mathrm{~min}$ at $37^{\circ} \mathrm{C}$.After washing with PBS, the grids were incubated with a second antibody, at dilution of 1:20 in PBS for 30 min at $37^{\circ} \mathrm{C}$. After brief washing with PBS, the sections were stained with $5 \%$ aqueous acetate for $5 \mathrm{~min}$.

Control experiments were performed by replacing the antiDNA antibody with antibody diluent.

\section{Immuno-gold labeling of anti-UBF antibody}

The anti-UBF antibody was a gift from Prof. MM. Valdivia (Department of Biochemistry and Molecular biology, Faculty of
Sciences, University of Cadiz, 11510 Puerto, Cadiz, Spain). Protein A conjugated to colloidal gold particles was purchased from Sigma. The assay of immuno-gold labeling was performed as described (9) with some modifications. Ultra-thin Lowicryl sections were mounted on formvar nickel grids and washed in PBS three times for 1 min each; and 5\% BSA (PBS, $0.05 \%$ Triton X-100) for $10 \mathrm{~min}$. Then the grids were incubated in anti$\mathrm{UBF}$ antibody diluted to 1:300 in PBS for $1 \mathrm{~h}$ at room temperature. After several washings in PBS, they were floated in protein A diluted to $1: 25$ in PBS for $45 \mathrm{~min}$ at room temperature. They were subsequently washed in PBS and distilled water. Finally, the sections were counterstained with 5\% uranyl acetate. Sections were observed in a Hitachi EM H-600B at $75 \mathrm{KV}$.

Controls were done, by replacing the anti-UBF antibody with antibody diluent.

\section{RESULTS}

\section{Nuclear bodies ultrastructure and their origin}

In order to observe clearly the nuclear bodies, we have first employed electron microscopic silverstaining technique to study the distribution of silver precipitates in onion cell nuclei. They were present all over the chromatin, nucleolus and nuclear bodies, but only the nucleolus and nuclear bodies were heavily stained (Fig 1).

Nuclear body appeared as a spherical structure about 0.3 to $0.8 \mu \mathrm{m}$ in diameter, and they varied in number from one to three per nuclear section (Figs 1, 2 arrows). Under high magnification, nuclear bodies appeared to be in form of a tangle of coiled threads with their electron density similar to nucleolus (Fig 2). This indicated that the nuclear bodies contained silver staining proteins. The locations of nuclear bodies were randomly distributed in the nucleoplasm (Fig 1), and sometimes in the vicinity of nuclear envelope (Fig 2). Under conventional staining conditions, onion interphase nuclei displayed conspicuous and irregularly chromatin strands and masses. However, the nuclear bodies appeared round with a fibrillar texture (Fig 3, 4).

We have also observed that the nuclear bodies were located at the surface or in the vicinity of nucleolus, e.g. Fig 3, which showed that two nuclear bodies were associated with the nucleolus. One was partly embedded in nucleolus but can be easily recognized owing to its round shape, and the other 
one located near the nucleolus. We have also observed that the nuclear body was emerged from the granular component of nucleolus (Fig 4). These results may imply that the nucleolus is the possible origin of nuclear body, which subsequently entered into nucleoplasm.

\section{Nuclear body structural component}

The above mentioned electron microscopic silver-staining experiment indicates that the nuclear bodies contain silver staining proteins. To gain fur-



Fig 1, 2. Electron micrographs of nuclei treated with silver staining, showing nuclear body contained silver-stainable proteins. Their location was free in the nucleoplasm (Fig 1), sometimes was in the vicinity of nuclear envelope (Fig 2). Under a high magnification, nuclear bodies displayed a fibrillar texture (Fig 2). Arrows indicated nuclear bodies. Triangle arrows indicated the position of nuclear envelope. Fig 1: 10,000 $\times$; Fig 2: 15,000×. ther information about the structural component of nuclear body, we have used EDTA regressive staining wethod, preferential for RNPs, to detect the RNP component from nuclear bodies in onion cells. The result showed that nuclear bodies appeared more darkly stained in contrast to the bleached chromatin regardless of their location (Fig 5). Under high magnification, we observed that there were some RNP components around the nuclear body. No structural connections were found between the bleached chromatin and nuclear body (Fig 6). Our result confirmed the presence of RNPs in nuclear
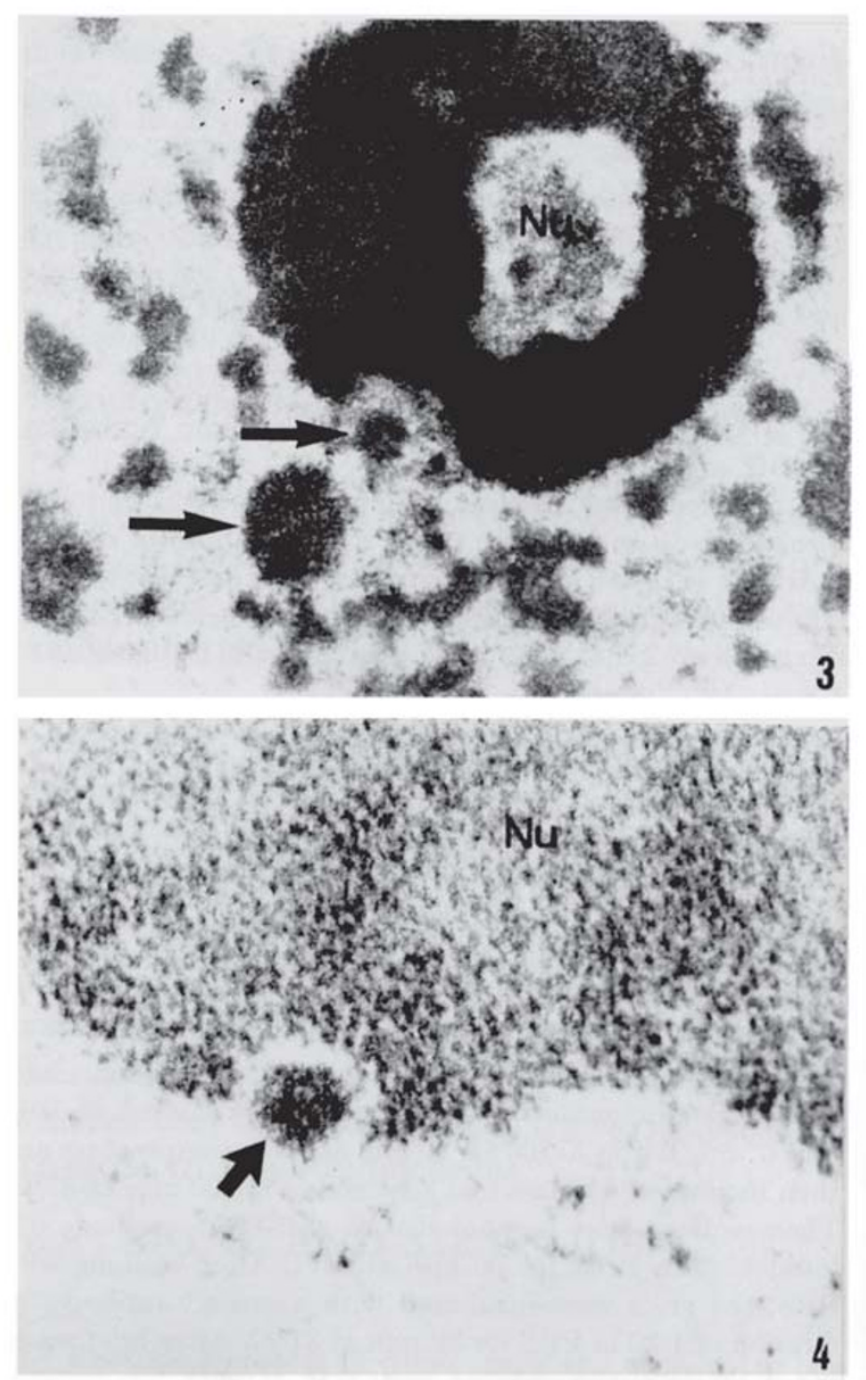

Fig3, 4. Electron micrographs of nuclei treated with conventional staining, showing two nuclear bodies were located at the surface or in the vicinity of nucleolus (Fig 3). The nuclear body was seen embedded in the granular component of nucleolus (Fig 4). Arrows indicated nuclear bodies. $\mathrm{Nu}$ : nucleolus. $15,000 \times$. 
bodies.

Incubation of onion root ultrathin sections with monoclonal antibody against DNA resulted in a specific labelling. Gold particles were mainly seen over the condensed chromatin. On the contrary, nuclear bodies were always free of labelling (Fig 7). No specific labelling signals were observed in control experiment in which sections were incubated in the absence of anti-DNA antibody (data not shown).

Because the nuclear bodies are sometimes closely associated with nucleolus, we further veri-
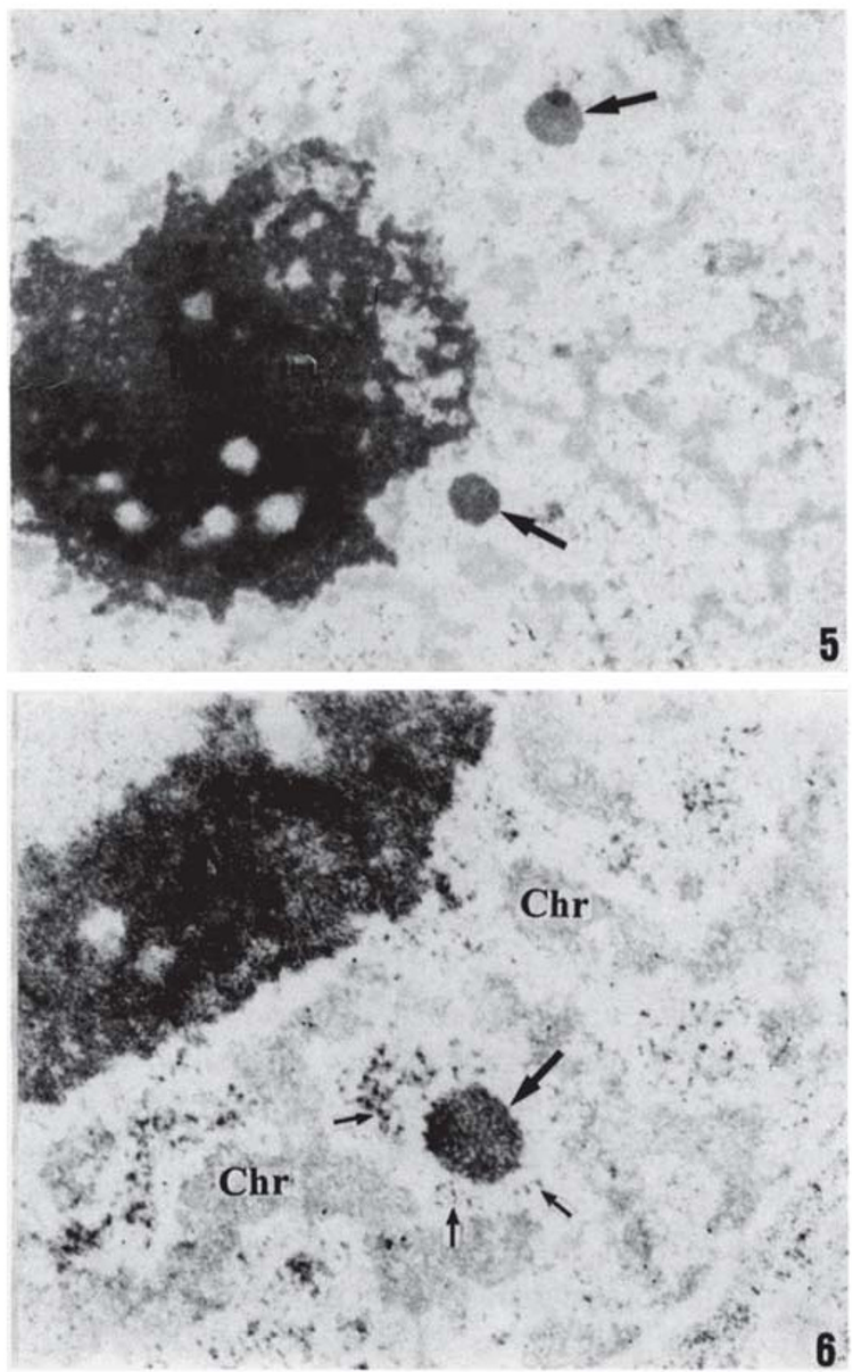

Fig5, 6. EDTA regressive staining for RNPs, showing that nuclear bodies contained RNPs. Nuclear body and nucleolus were heavily stained (Fig 5, 10,000 $\times$ ) and surrounded by RNP components but not connected with chromatin (Chr) (Fig 6, 17,000×). Large arrows indicated nuclear bodies. Small arrows indicated RNP components. Nu: nucleolus. fied if the nuclear bodies are related to the transcription activity of rRNA genes in nucleolus. The best-characterized factor involved in ribosomal transcription activity is UBF (upstream bind factor), which binds to two regions of the rDNA promoter region, the upstream control elements and the core promoter[10]. We performed immunogold labelling with anti-UBF antibody on onion root ultrathin sections. The electron micrographs showed that gold particles were present preferentially over the nucleolus, while no labelling signals were observed over nuclear body in the vicinity of nucleolus, and
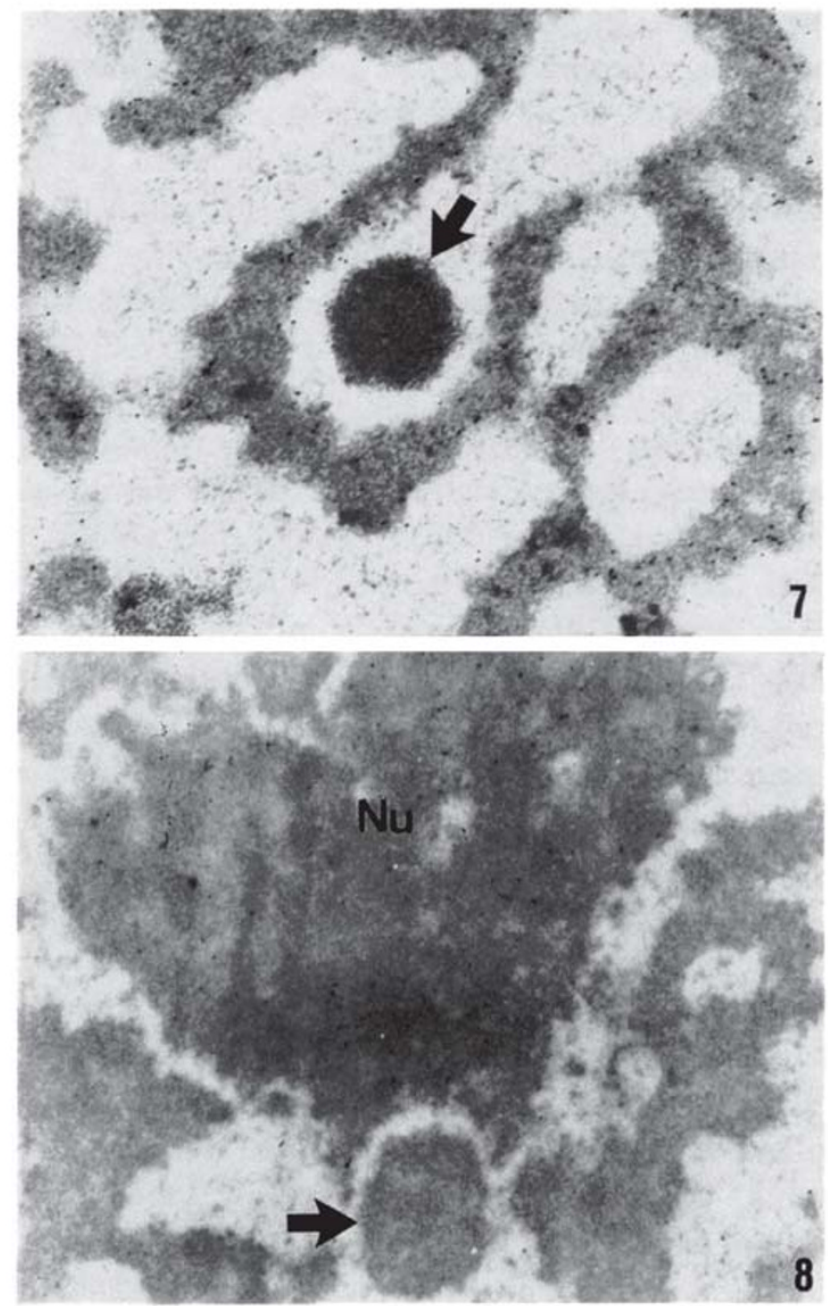

Fig7, 8. Detection of DNA (7) and UBF (8) in nuclear body of onion nuclei. Fig 7 The condensed chromatin masses were intensely labeled, but nuclear body was completely free from labelling. Fig 8 Gold particles were observed over the nucleolus, but none over the nuclear body and the nucleoplasm. Nu: nucleolus. 20,000 $\times$. 
the nucleoplasm was chiefly free from labelling (Fig 8).

\section{DISCUSSION}

In many plant species, interphase nuclei of meristematic cell display some nuclear bodies that are distributed throughout the nucleoplasm. These bodies have been referred to as coiled bodies, karyosomes, micronucleoli and nucleolus-associated bodies[2-4]. One intriguing question concerning nuclear bodies is their origin in interphase nuclei. Earlier ultrastructural observations indicated that they exhibited a characteristic texture and sometimes are located at the immediate vicinity of the nucleolus[11]. Some recent studies also support the association of some nuclear bodies with the nucleolus surface, and therefore hypothesize that nuclear bodies are originated from nucleolus[7]. However, examination of serial sections under electron microscope revealed no connection between the nuclear body and nucleolus[12], so the origin of nuclear body still remains somewhat obscure.

Our results showed that, in nuclei of onion cells, nuclear body appeared as a spherical structure about 0.3 to $1.2 \mu \mathrm{m}$ in diameter, with the similar electron density as the nucleolus when stained with uranyl-lead and silver nitrate. Our results also showed that nuclear bodies are not only associated with the nucleolus and located at the vicinity of nuclear envelope, but also partly embedded in nucleolus. The similar results were also obtained in other cells[6], [7]. Like some other authors, we also tend to suggest that the nuclear bodies may be originated from nucleolus, then they subsequently entered into the nucleoplasm.

In order to understand the role of the nuclear bodies in interphase nuclei, it is important to explore their structural component at the ultrastructural level. According to the early report from Sankaranayanan and Hyde[13], nuclear bodies in plant cells were composed of DNA, RNA and proteins, this result was confirmed by labelling experiment with the DNAse-gold technique[14]. Lafontaine and Chamberland also indicated that nuclear bodies were DNA-containing structures, and somewhat related to the nucleolar chromosomes, namely nuclear body was the terminal segment of nucleolar chromosome[12]. Based on confocal microscopic study, Rawlins and Shaw revealed the presence of ribosomal DNA in interphase nuclear bodies[15]. However, more recent evidences obtained by immunocytochemical studies indicated that nuclear body contain no DNA component but only RNPs and proteins[6],[7], and snRNPs were found especially present in nuclear bodies in green pea cells[16].

The present work has examined the structural component at the ultrastructural level in nuclear bodies of onion cells. Our results showed that nuclear bodies are silver stainable and more darkly stained in contrast to the bleached chromatin when treated with EDTA regressive staining, these results confirmed the presence of RNP and proteins in nuclear bodies. But we noted that there were no structural connections between nuclear bodies and chromatin. By using anti-DNA antibody, we also failed to detect the DNA in nuclear bodies as report from Lafontaine[12]. So it may be concluded that nuclear bodies indeed contain RNPs and proteins, but they do not contain DNA component. Since present data, as well as those of other authors also on plant cells have lead to contrary results, we proposed that nuclear body either contains no DNA or that the DNA amount in nuclear body can not be detectable with the technique present used. Further study is therefore required using more sensitive labelling techniques.

The function of nuclear bodies is still unknown. Although nuclear bodies have been observed in the vicinity of nucleolus, it is still not determined at present whether they are related to the transcription activity of rRNA genes in nucleolus. To clarify this point, we examined whether the ribosomal transcription factor (UBF) is present in nuclear bodies, and the result is negative. We found that $\mathrm{UBF}$ is distributed only in nucleolus, whereas nuclear bodies in the immediate vicinity of nucleolus were free of labelling. Considering that nuclear bodies are RNPs-contained structures, we suggested that they may not be related to the ribosome or other gene transcription activities, but may act as subnuclear structures for RNPs transport from nucleolus to cytoplasm. Finally, since snRNP 
are localized in the nuclear bodies[16], another possible function of these bodies may be their involvement in splicing of pre-mRNA.

\section{ACNOWLEDGMENTS}

This project was suported by China postdoctoral Science foundation.

\section{REFERENCES}

[1] Lamond AI, Earnshaw WC. Structure and function in the nucleus. Science 1998; 280:547-53.

[2] Lafontaine JG. A light and electron microscope study of small, spherical bodies in meristematic cells of Allium cepa, Vicia faba and Raphanus sativus. J Cell Biol 1965; 26:1-17.

[3] Moreno Diaz de la Espina S, Risueno MC, Medina FJ. Ultrastructural, cytochemical and autoradiographic characterization of coiled bodies in plant cell nucleus. Biol Cell 1982; 44:229-38.

[4] Lafontaine JG, Luck BT, Gugg S. Nucleolus-associated bodies in meristematic cells of two plant species with different ploidy levels. Can J Bot 1991; 69:1329-36.

[5] Barlow PW. Nucleolus-associated bodies (karyosomes) in dividing and differentiating plant cells. Protoplasm, 1983; 115:1-10.

[6] Gulemetova R, Chamberland H, Gugg S, et al. Presence of small- ribonucleoprotein- containing nuclear bodies in quiescent and early germinating Zea mays embryos. Protoplasm 1998; 192-201. [7] Jennane A, Thiry M,
Goessens G. Identification of coiled body-like structures in meristematic cells of Pisum sativum cytotyledonary buds. Chromosoma 1999; 108:132-42.

[8] Bernhard W. A new staining procedure for electron microscopical cytology. J Ultrastruct Res 1969; 27:25065.

[9] Zeng XL, Jiao MD, Xing M, Wang XG, Hao S. Tropomyosin is localized in the nuclear matrix and chromosome scaffold of Physarm polycephalum. Cell Research 1999; 9: 61-9.

[10] Shaw PJ, Jordan GE. The nucleolus. Annu Rev Cell Dev Biol 1995; 11:93-121.

[11] Xing M, Hao S, Tong DJ. Studies on the mininucleolus in nuclei of meristematic cells of Vicia faba. Acta Botanica Sinica 1989; 31(1):19-23.

[12] Lafontaine JG, Chamberland H. Relationship of nucleolus-associated bodies with the nucleolar organizer tracks in plant interphase nuclei. Chromosoma 1995; 103:54553.

[13] Sankaranayanan K, Hyde BB. Ultrastructural studies of a nuclear body in peas with characteristics of both chromatin and nucleoli. J Ultrastruct Res 1965; 12:748-61.

[14] Williams LM, Charest PM, FitzGerald GJ, Lafontaine JG. A comparison of nuclease-gold and protease -gold complex labelling over the nucleolus and nuclear bodies of Pisum sativum root tip cells. Biol Cell (Paris) 1985; 54: 65-72.

[15] Rawlins DJ, Shaw PJ. Three-dimensional organization of ribosomal DNA in interphase nuclei of Pisum sativum by in situ hybridization and optical tomography. Chromosoma 1990; 99:143-51.

[16] Chamberland H, Lafontaine JG. Localization of snPNP antigens in nucleolus-associated bodies: study of plant interphase nuclei by confocal and electron microscopy. Chromosoma 1993; 102:220-36. 